\title{
Phase separation in mixed monolayers of arachidic acid and a phthalocyanine of zinc
}

\author{
J. Torrent-Burgués \\ Department of Chemical Engineering, Universitat Politècnica de Catalunya (UPC) \\ C/ Colom 1, 08222 Terrassa (Barcelona), Spain \\ E-mail: juan.torrent@upc.edu
}

Tlf.: 34-937398043, Fax: 34-937398225

\begin{abstract}
Mixed Langmuir and Langmuir-Blodgett films of dissimilar components, arachidic acid and a phthalocyanine of zinc, have been investigated. These compounds form mixed films with phase separation, with domains at the sub-micro scale which are detected by AFM in LB films but not observed by BAM. These domains present different contrast in the surface potential images obtained with SP-AFM and in the friction images. The analysis of the isotherms and of the AFM images, at several compositions, reveals that the components are immiscible. The difference in height between the arachidic acid and the phthalocyanine of zinc phases is in accordance with the heights of the molecules, and points to the presence of a monolayer in the zinc phthalocyanine phase. AFM has revealed as a necessary technique to elucidate the miscibility in mixed films at the nanometric scale. UV-Vis spectroscopy shows changes in the spectra bands of LB films in respect to those in solution, due to the organization of the molecules in the LB film.
\end{abstract}

Keywords: mixed monolayers, phase separation, BAM, Langmuir-Blodgett, AFM, surface potential. 


\section{Introduction}

The study of mixed films of dissimilar components [1-19] is of practical interest due to the fact that a great number of compounds of technological interest need a film former. Phthalocyanines (Pc), porphyrins (P), metallo-porphyrins (MP) and metallophthalocyanines (MPc) are an example. Fatty acids have been investigated as film formers in mixed films with macrocyclic compounds, and the transfer to a substrate by the Langmuir-Blodgett (LB) technique of a MPc or MP can be improved by the presence of a fatty acid which acts as a transfer promoter [5, 6]. Usually a minimum percentage of fatty acid is required. Sheu et al. [6] used arachidic acid (AA) as fatty acid, and molar ratios for mixed CuPc:AA of 1:1, 2:1 and 4:1 where the MPc predominates, but Peng et al. [5] used molar ratios for CuP:Cd Arachidate with high molar fraction of $\mathrm{Cd}$ Arachidate $(\geq 0.8)$ in order to obtain quality films. High proportions of AA were also used by Lu et al. [3] in mixed films of Ru(dpphen) ${ }_{3}{ }^{2+}: \mathrm{AA}$, and found that the best mixture ratio for the stable mixed monolayer is 1:2. Del Caño et al. [7] have studied mixed films of titanyl(IV)Pc and AA using molar ratios of 1:1 and 1:4, thus also with a high proportion of AA.

The topographic mode of Atomic Force Microscopy (AFM) has become a general technique in the study of mixed Langmuir-Blodgett (LB) films, while a related technique such as surface potential-AFM (SP-AFM) has been scarcely used. These techniques provide useful information on the structure of the films, topographically or compositionally. Changes in the response of the different domains of the film can be attributed to differences in chemical composition, in structure or in molecular orientation. Phase separation is an important point to be considered in the film structure of mixed films, and these techniques can provide a powerful tool to investigate them, especially when domains present micrometric or nanometric size.

In mixed films of a macrocyclic compound, such as a phthalocyanine or a porphyrin, with a fatty acid, such as AA, an increase in the area per molecule has been observed [3, 4, 7] despite the small value of this parameter for fatty acids. Complemented with results of RAIRS, UV-Visible absorption and micro-Raman imaging, this phenomenon has been explained by a change in the molecular orientation of the macrocycle induced by the presence of the fatty acid. An increase in the area has also been observed in a mixed film of a thiomacrocyclic compound with AA [16, 17], 
which has been attributed to a partial solubility of AA in the thiomacrocycle phase with a loss of compactness, and in a mixed film of a nitrostilbene derivative with behenic acid [10], which has been attributed to the ability of behenic acid to prevent aggregation of the nitrostilbene derivative. In other cases a decrease in the area per molecule has been observed $[9,12]$, which has been attributed to the fact that fatty acid molecules can enter into the macrocyclic ring [12] or to the formation of a condensed phase [9]. Other authors [13] have found that the miscibility of an azacrown ether with palmitic acid depends on the surface pressure, and reported that miscibility occurs at intermediate pressures, at least on the macroscopic level based on the BAM observation of film homogeneity. As the behaviour of mixed films is not clear a priori, it must be investigated in each case.

Pc and MPc have been used for many years as blue and green dyes, but recently they have also been investigated for their applications as catalysts and chemical sensors, as photosensitizers, in solar cells, and in electronic and photonic technologies [20-25]. In particular, zinc phthalocyanines $(\mathrm{ZnPc})$ have received some attention [26] and recent investigations target applications in photodynamic therapy [27-29] or as promising materials for organic solar cells [25]. These applications usually require a thin film deposited on a solid substrate. Several studies have investigated these systems and their particular structure, and some of them have studied the characteristics of organized Langmuir and Langmuir-Blodgett (LB) films [1, 20, 30-35]. Studies in LB films of MPc are important in understanding of interfacial spectroscopic processes occurring in organic materials deposited on inorganic solid substrates, for further developing of photovoltaics and optoelectronic devices. One of the characteristics of these compounds is the strong aggregation they present and the difficulty with which they form homogeneous films. Low aggregation in $\mathrm{ZnPc}$ is important since aggregation causes drastic decay of optical properties [36]. Consequently, further investigation about the influence of fatty acids in the film formation of $\mathrm{ZnPc}$ is necessary, and to the author knowledge, no studies with this objective have been reported for PcZn.

The compound zinc tetra-tert-butylphthalocyanine (tbuPcZn) has a high value for the molar absorption coefficient, $\varepsilon=19.7310^{4} \mathrm{M}^{-1} \mathrm{~cm}^{-1}$ at $\lambda=675 \mathrm{~nm}$ (calculated by the author), and, on the other hand, is very soluble in chloroform, fact that facilitates the film formation at the air-water interface. These properties are of interest for investigating the applicability of this compound in photodynamic therapy or in thin films for solar cells. 
This work studies the influence of arachidic acid in the film formation of the phthalocyanine tbuPcZn, and whether phase separation occurs. Several film compositions have been analyzed by using surface pressure-area isotherms, Brewster angle microscopy (BAM), UV-Vis spectroscopy, AFM and SP-AFM, in order to study the characteristics of the mixed films and conditions for a good film formation. In particular the scanning probe microscopy techniques provide the necessary information about the possibility of using AA as a transfer promoter, and the structure of the films at a nanometric scale. The UV-Vis spectroscopy has been used for observing the changes in the spectra of LB films in respect to those in solution.

\section{Experimental}

Langmuir films were obtained in a NIMA 1232D1D2 Langmuir-Blodgett trough and BAM images were obtained with a microBAM model (NIMA-Nanofilm), which has a lateral resolution of around $8 \mu \mathrm{m}$, both placed on an isolation platform. Pure water (Millipore MilliQ grade) was used as subphase, arachidic acid, AA (M=312.0), and zinc 2,9,16,23-tetra-tert-butyl-29H,31H-phthalocyanine (Scheme 1), tbuPcZn (M=802.34), were supplied by Sigma-Aldrich. A solution of pure component or mixed AA and tbuPcZn in chloroform was spread over the water subphase, and 15 min were allowed before compression in order to permit evaporation of the chloroform and stabilization. The compression speed was in between 1.3 and $1.8 \AA^{2} /$ molec.min. Basically, three compositions have been studied: $C_{\text {tbuPcZn }}=0.455 \mathrm{mg} / \mathrm{mL}, \quad \mathrm{C}_{\mathrm{AA}}=0.50 \mathrm{mg} / \mathrm{mL}$ $\left(\mathrm{C}_{\mathrm{tbuPcZn}} / \mathrm{C}_{\mathrm{AA}} \approx 1: 1\right), \mathrm{X}_{\mathrm{AA}}=0.74\left(\mathrm{X}_{\mathrm{AA}} / \mathrm{X}_{\mathrm{tbuPcZn}}=2.8\right)$, where $\mathrm{X}$ refers to the molar fraction; $\mathrm{C}_{\text {tbuPcZn }}=0.303 \mathrm{mg} / \mathrm{mL}, \quad \mathrm{C}_{\mathrm{AA}}=0.666 \mathrm{mg} / \mathrm{mL} \quad(\approx 1: 2), \quad \mathrm{X}_{\mathrm{AA}}=0.833 \quad\left(\mathrm{X}_{\mathrm{AA}} / \mathrm{X}_{\mathrm{tbuPcZn}}=5.0\right)$; $\mathrm{C}_{\mathrm{tbuPcZn}}=0.606 \mathrm{mg} / \mathrm{mL}, \mathrm{C}_{\mathrm{AA}}=0.333 \mathrm{mg} / \mathrm{mL}(\approx 2: 1), \mathrm{X}_{\mathrm{AA}}=0.59\left(\mathrm{X}_{\mathrm{AA}} / \mathrm{X}_{\mathrm{tbuPcZn}}=1.4\right)$. Mixed films with lower AA proportions have also been used but no good films were obtained. The LB films were transferred at constant pressure onto a freshly cleaved atomically flat mica surface. The transfer was done using a NIMA 1232 D1 dipper, at a surface pressure of $20 \mathrm{mN} / \mathrm{m}$. The mica substrates were sheets of $1 \mathrm{~cm} \times 1 \mathrm{~cm}$ cut from red mica. LB films were obtained following a $Z$ deposition at a speed of $5 \mathrm{~mm} / \mathrm{min}$. For tbuPcZn the transfer ratio was slightly higher than $100 \%$, and with the presence of AA 
the transfer ratio became closer to $100 \%$. The experiments were done at a temperature of $23^{\circ} \mathrm{C}$.

AFM images and friction images were performed with a Multimode atomic force microscope attached to a Nanoscope IV controller (Digital Instruments, Santa Barbara, CA). The microscope was placed on a $\mathrm{N}_{2}$-operated vibration isolation table. Topographic images were acquired in tapping mode using Si tips with a nominal vertical spring constant of $40 \mathrm{~N} / \mathrm{m}$. Friction images, and the corresponding topographic images, were acquired in contact mode using silicon nitride tips of low spring constant [37]. Surface potential measurements were performed with a conducting Sb-doped Si tip with a nominal vertical spring constant of $1-5 \mathrm{~N} / \mathrm{m}$ in non-contact mode. In that case, tapping topographic images and surface potential images were adquired using the LiftMode [38], which compensates for the height variations on the sample during SP imaging by using a two-pass technique. In SP imaging, sometimes referred to as Scanning Kelvin Probe Microscopy (SKPM), a conductive AFM tip interacts with the sample through long-range Coulomb forces. These interactions change the oscillation amplitude and phase of the AFM cantilever which are detected to create SP images [38]. UV-Vis spectra were obtained from chloroform solutions and from LB films, using a conventional UV-Vis spectrophotometer.

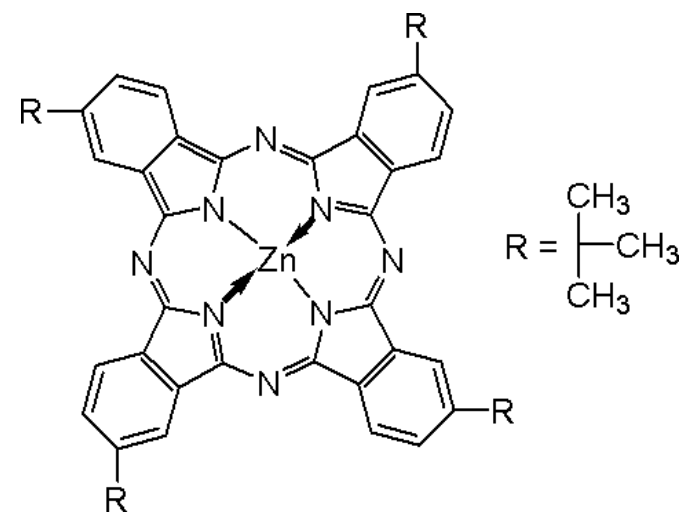

Scheme 1. Molecular structure of the zinc 2,9,16,23-tetra-tert-butyl-29H,31H-phthalocyanine. 


\section{Results and discussion}

Figure 1 shows the surface pressure-area isotherms for mixed films of AA and tbuPcZn. The mean area per molecule, considering the total number of molecules, is plotted in the $\mathrm{X}$ axes. The AA isotherm shows the usual shape; with a phase change from liquid condensed (LC) to solid (S) state at a surface pressure ca. $26 \mathrm{mN} / \mathrm{m}$. The tbuPcZn isotherm shows an initial region with relatively high values of the compressibility coefficient $\left(\beta=-1 / \mathrm{A}(\delta \mathrm{A} / \delta \Pi)_{\mathrm{T}}\right)$ which corresponds to a liquid expanded (LE) state [39]. For instance, $\beta=0.019 \mathrm{~m} / \mathrm{mN}$ at $\Pi=8 \mathrm{mN} / \mathrm{m}$. At surface pressures above $15 \mathrm{mN} / \mathrm{m}$, the values of $\beta$ correspond to a $L C$ state, for instance $\beta=0.009 \mathrm{~m} / \mathrm{mN}$ at $\Pi=32$ $\mathrm{mN} / \mathrm{m}$. In the studied mixtures, the isotherm slopes, and the $\beta$ values, get closer to that of pure AA than that of tbuPcZn. For instance, $\beta$ values are $0.010 \mathrm{~m} / \mathrm{mN}$ for pure AA and all the mixtures, at $\Pi=8 \mathrm{mN} / \mathrm{m}$, and $0.004 \mathrm{~m} / \mathrm{mN}$ for AA and $1: 2$ and $1: 1$ mixtures, and $0.005 \mathrm{~m} / \mathrm{mN}$ for the $2: 1$ mixture, at $\Pi=32 \mathrm{mN} / \mathrm{m}$.

The AA presents a collapse at a surface pressure of $55 \mathrm{mN} / \mathrm{m}$, with a sharp decrease of this value, which is clearly visible in BAM images with the breaking of the film (Figure 2A-b). On the other hand, isotherms of tbuPcZn and mixtures show a marked inflexion at $\Pi$ around $41-43 \mathrm{mN} / \mathrm{m}$ and the slope decreases. This could indicate a collapse of the monolayer, according to Souto et al. [35] who obtained a similar isotherm for its system. BAM images for tbuPcZn (Figure 2A-d) show, at these pressures, collapse with breaking of the film. BAM images for tbuPcZn (Figure 2A-c) also show an irregular film at surface pressures below the collapse, meanwhile for AA show a uniform film (Figure 2A-a). For the mixtures, as the surface pressure continues increasing after the inflexion, a multilayer formation or a change in the molecular orientation could take place. Finally, another inflexion appears at $\Pi>50 \mathrm{mN} / \mathrm{m}$. BAM images of these mixed films (Figure 2B) show that, at the lateral resolution of the used BAM, the film appears uniform with only some imperfections in zone $\Pi<42 \mathrm{mN} / \mathrm{m}$ (Figure $2 \mathrm{~B}$-a and b), remaining uniform after that $\Pi$ and until $\Pi<50 \mathrm{mN} / \mathrm{m}$ (Figure 2Bc). This observation indicates that a catastrophic collapse does not occur at $\Pi$ around 41-43 $\mathrm{mN} / \mathrm{m}$, due possibly to a multilayer formation or due to orientation or organization changes in the molecules, but this cannot be clearly distinguished in the used BAM due to its limited resolution. Only at very high compressions, $\Pi>50 \mathrm{mN} / \mathrm{m}$, 
fringes appears in the film (Figure 2B-d), probably due to a macroscopic phase separation.

Figure 1. Surface pressure-mean area per molecule isotherms for mixtures of arachidic acid (AA) and tetra-tert-butylphthalocyanine of zinc (tbuPcZn) at $23^{\circ} \mathrm{C}: 1$ ) pure tbuPcZn, 2) $\left.\mathrm{X}_{\mathrm{AA}}=0.59,3\right) \mathrm{X}_{\mathrm{AA}}=0.74$, 4) $\left.\mathrm{X}_{\mathrm{AA}}=0.833,5\right)$ pure $\mathrm{AA}$. Inset: Mean area per molecule versus composition for mixtures of AA and tbuPcZn at $\Pi=30 \mathrm{mN} / \mathrm{m}$ (straight line corresponds to the additivity rule).

Figure 2A. BAM images (3.6 mm x $4.1 \mathrm{~mm}$ ) of an AA film at $\Pi=17$ (a) and $55 \mathrm{mN} / \mathrm{m}$ (collapse) (b), and of a tbuPcZn film at $\Pi=21$ (c) and $43 \mathrm{mN} / \mathrm{m}$ (collapse) (d).

Figure 2B. BAM images, size $2.2 \mathrm{~mm} \times 2.2 \mathrm{~mm}$, for the mixed film of AA and tbuPcZn

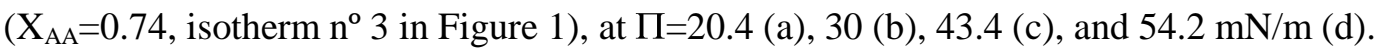

The additivity rule is expressed by equation (1), where $\mathrm{x}_{\mathrm{i}}$ is the mol fraction and $\mathrm{A}_{\mathrm{i}}$ the area per molecule in the individual film at a given pressure. This equation is used together with the experimental area values for the analysis of the mean area versus molar fraction, at several surface pressures.

$$
\mathrm{A}_{\mathrm{ad}}=\mathrm{x}_{1} \mathrm{~A}_{1}+\mathrm{x}_{2} \mathrm{~A}_{2}
$$

The experimental values follow a linear dependence and fit well with the values calculated with the additivity rule of equation (1) till $\Pi<42 \mathrm{mN} / \mathrm{m}$. Inset in Figure 1 shows that for the particular case of $\Pi=30 \mathrm{mN} / \mathrm{m}$. This result indicates that the components form an ideal mixed film or are immiscible. In order to elucidate this point more clearly, LB films were transferred onto mica substrates and observed by AFM.

Langmuir films show good stability with time presenting, for instance at $\Pi=20$ $\mathrm{mN} / \mathrm{m}$, an area reduction of $2.5 \%$ after 20 minutes. This value is lower than that of $6 \%$ 
presented by tbuPcZn alone. LB films at $\Pi=20 \mathrm{mN} / \mathrm{m}$ were transferred onto mica for the different compositions of the mixed films. AFM images in topographic (shown in Figure 3) and phase modes (not shown) were obtained at several zones in each film. The presence of domains with higher height and lower phase contrast was observed. Friction images (not shown) also present these domains, in correspondence with the topographic images, which have a lower friction signal. As the number of domains and their total area increases with the AA percentage, we can assume that these high domains correspond to AA. The lower friction signal of AA domains was also observed previously [16] in mixed films of AA with another macrocyclic compound. Calculating, over several AFM images, the surface coverage for the AA domains at the different compositions, the values of $31 \pm 5 \%, 45 \pm 5 \%$ and $64 \pm 5 \%$ were obtained for the $2: 1,1: 1$ and 1:2 $\mathrm{C}_{\mathrm{tbuPcZn}} / \mathrm{C}_{\mathrm{AA}}$ compositions $\left(\mathrm{X}_{\mathrm{AA}}=0.59,0.74\right.$ and 0.833). Calculating, respectively, the expected surface coverage values for the mixed films from the values of area in the $\Pi$-A isotherms for pure components and the molar fractions, according to equation (2),

$$
\% \text { Area }_{1}=100 \mathrm{x}_{1} \mathrm{~A}_{1} /\left(\mathrm{x}_{1} \mathrm{~A}_{1}+\mathrm{x}_{2} \mathrm{~A}_{2}\right)
$$

the values of $32.5 \%, 48.5 \%$ and $62 \%$ were obtained. Both sets of values agree, indicating definitively that AA and tbuPcZn form separate phases and that are immiscible. Immiscibility has also been observed by Peng et al. [5] in mixed films of cadmium arachidate (CdAr) and a porphinatocopper(II), but Cheng et al. [12] have found no phase separation in the mixed films of stearic acid (SA) and a crown ether, a fact that was attributed to the possibility that SA molecules can enter into the crown ether ring. Our system behaves more similarly to that of Peng et al. [5]. An extra observation is that the AA domains decrease in size when the AA proportion increases from $\mathrm{X}_{\mathrm{AA}}=0.59$ (mean diameter $\left.\varnothing=0.49 \mu \mathrm{m}\right)$ to $\mathrm{X}_{\mathrm{AA}}=0.74(\varnothing=0.25 \mu \mathrm{m})$, but for the $\mathrm{X}_{\mathrm{AA}}=0.833$ the size increases again $(\varnothing=0.44 \mu \mathrm{m})$; a similar fact was also observed in other mixed films of AA with a different macrocycle [16], but for the moment the author does not have an explanation for these observations. Figure 4 shows the size distribution for the different compositions obtained from several AFM images; sizes do not present a perfect Gaussian distribution but there are some sizes around the mean 
value with higher frequencies and it is also observed that the distribution for the mixed film with $\mathrm{X}_{\mathrm{AA}}=0.74$ is less wide.

Figure 3. AFM images, size $5 \mu \mathrm{m}$ x $5 \mu \mathrm{m}$, of LB films transferred onto mica at $\Pi=20 \mathrm{mN} / \mathrm{m}$ of mixed AA and tbuPcZn: $\mathrm{X}_{\mathrm{AA}}=0.59$ (a), 0.74 (b), and 0.833 (c). As is discussed in the text, domains, which are higher, corresponds to AA.

Figure 4. Size distribution of AA domains observed by AFM in the mixed films: $X_{\mathrm{AA}}=0.59$ (black), 0.74 (white), and 0.833 (grey). $\mathrm{X}$ axe represents the domain diameter, $\varnothing$, and $\mathrm{Y}$ axe the relative frequency, f. Measurements were made over several AFM images.

The AA domains have a height of around $0.7 \mathrm{~nm}$ in respect to the tbuPcZn phase. We have found in previous studies $[16,40]$ that, at this surface pressure value, AA molecules present a height of $2.2 \mathrm{~nm}$ with a tilt angle of $32^{\circ}$. This leads to a calculated height of $1.5 \mathrm{~nm}$ for the tbuPcZn molecules. The molecular dimensions of the tbuPcZn are close to a square of $1.52 \mathrm{~nm}$ side [20] for the ring, and a value of around $0.40 \mathrm{~nm}$ in the perpendicular direction. Consequently a tilt angle close to $0^{\circ}$ is obtained, that is the tbuPcZn molecules dispose themselves in an edge-on orientation (the phthalocyanine ring perpendicular to the surface). This edge-on orientation is coherent with the area per molecule, $65 \AA^{2}$ at $\Pi=20 \mathrm{mN} / \mathrm{m}$, displayed in the $\Pi$-A isotherm of the tbuPcZn, and coincides with the perpendicular orientation reported by Peng et al. [5] for a similar system but with a porphinatocopper, mixed with CdAr, which was obtained by using grazing incidence X-ray diffraction. These results contrast with that reported by Del Caño et al. [7] in mixed films of titanyl(IV) phthalocyanine (TiOPC) and AA. These authors found an increase in the area per molecule and that in the presence of AA the TiOPc molecules adopt a preferential flat-on orientation. Some authors $[1,12]$ have reported that for other mixtures of dissimilar components, an amphiphilic long-chain compound and a macrocycle with long-chain substituents, on compression the longchain compound disposes itself on top of the macrocycle layer, forming a two-layer film. But our observations point to a monolayer with two separate phases. This behaviour can be facilitated by the edge-on orientation of the phthalocyanine molecules 
and the lack of long-chain substituents in the ring. The practically constant value for the difference in height between the AA and tBuPcZn phases also points to the presence of a monolayer in the tBuPcZn phase. This is an interesting result since Pc molecules tend to aggregate and form non-uniform or multilayer films. Figure 5 shows an AFM image of a neat tbuPcZn film where the formation of a non-uniform film is clearly seen. AA favours the formation of a more uniform phase for tbuPcZn, even though a phase separation occurs between both components. BAM and AFM images (not shown) of mixed films with a high proportion of tbuPcZn (for instance $\mathrm{C}_{\mathrm{tbuPcZn}} / \mathrm{C}_{\mathrm{AA}}=3.6: 1$, $\mathrm{X}(\mathrm{AA})=0.42$ ) reveals that then non uniform films form; consequently a high proportion of AA is necessary to be present in order to obtain a uniform tbuPcZn phase.

Figure 5. AFM image $\left(2 \times 2 \mu \mathrm{m}^{2}\right)$ of a LB film of tbuPcZn at $\Pi=20 \mathrm{mN} / \mathrm{m}$.

Surface potencial images were also recorded with an AFM using suitable tips and the non-contact mode. Figure 6 shows the surface potential and the corresponding topographic images. A good correspondence between both images is observed, with the AA domains presenting lower surface potential. This result agrees with what can be expected from the molecular characteristics of the AA and tbuPcZn molecules. Pthalocyanine molecules have a strong $\pi$ system which can be polarized, and it is responsible for phthalocyanine films presenting higher surface potentials, as has been observed in Langmuir films of several phthalocyanines [41-43].

Figure 6. Topographic-AFM (a) and surface potential-AFM (b) images $\left(5 \times 5 \mu \mathrm{m}^{2}\right)$ of a LB film, transferred on mica at $\Pi=20 \mathrm{mN} / \mathrm{m}$, of mixed AA and tbuPcZn $\left(\mathrm{X}_{\mathrm{AA}}=0.833\right)$. Lower surface potential is observed in the AA domains.

UV-Vis spectra in figure 7 show that LB films present a decrease in the Q-band (red zone of the spectra) in respect to the Soret-band (near-UV zone) when compared with the spectra in solution, which has also been observed in others Pc [36, 44]. These facts are due to the organization, orientation, of the molecules in the LB film. The Q- 
band is broader in the LB film and it is also observed some changes in the secondary peaks of the Q-band, with a slight shift in the wavelength and a higher relative intensity (Table 1), suggesting aggregation effects.

Figure 7. UV-Vis spectra for tbuPcZn in a $0.610^{-5} \mathrm{M}$ solution (thin line) and in a one-layer LB film (thick line).

Table 1. Peak wavelengths and relative intensities from the UV-Vis spectra of tbuPcZn.

\begin{tabular}{|l|l|l|}
\hline & Solution & LB film \\
\hline & $\lambda$ peak (relative intensity) & $\lambda$ peak (relative intensity) \\
\hline Q-Band & $675(1)$ & $675(0.827)$ \\
\hline & $650(0.095)$ & $635(0.748)$ \\
\hline & $610(0.113)$ & \\
\hline Soret-band & $345(0.286)$ & $335(1)$ \\
\hline & $285(0.063)$ & $285(0.173)$ \\
\hline
\end{tabular}

\subsection{Ageing of LB films}

LB films show small or no changes after two weeks, with the coalescence of only some small domains into bigger ones in some but not in all the AFM images. After two months, changes are more notable and a lot of domains have coalesced, the domains becoming bigger as can be seen comparing Figure 8a with Figure $3 \mathrm{~b}$. This means that the films have certain fluidity, and when two AA domains come into contact a coalescence process occurs in order to minimize the line tension [45]. A close observation of the AA domains shows the presence of two heights in some domains (Figure 8a), which can be attributed to a reorganization of the AA molecules, with some of them changing the tilting angle. Thus a new phase formed in the domains of AA, which shows a height of around $0.4 \mathrm{~nm}$ lower than the previously observed of $2.2 \mathrm{~nm}$. In accordance with a former study of AA [40], this lower height of $1.8 \mathrm{~nm}$ corresponds to a tilting angle of $48^{\circ}$. From this observation, it seems that during ageing and coalescence there is a relaxation process in the tilting angle of the AA molecules. 
Friction images (Figure 8b) show a lower friction signal in the AA domains in respect to the tbuPcZn phase and with very low or no significant differences in between the zones of different height inside the AA domains.

Figure 8. Topographic-AFM (a) and friction (b) images $\left(5 \times 5 \mu \mathrm{m}^{2}\right)$ of an aged sample, two months, of mixed AA and tbuPcZn $\left(\mathrm{X}_{\mathrm{AA}}=0.74\right)$. Lower friction is observed in the AA domains.

\section{Conclusions}

Arachidic acid and zinc tetra-tert-butylphthalocyanine compounds form mixed films with phase separation, with domains at the sub-micro scale. The analysis of the isotherms (Figure 1) and of the AFM images (Figure 3), at several compositions, reveals that the components are immiscible. The coverage of the domains increases with the arachidic acid content. AFM is a powerful technique to observe immiscibility with domains at the sub-micrometric scale. The difference in height between the AA and tbuPcZn phases points to the presence of a monolayer in the tbuPcZn phase. This is an interesting result since Pc molecules tend to aggregate and to form non-uniform or multilayer films. These results can help in future researches of the author' group, connecting the electrochemical and photoelectrochemical response of $\mathrm{ZnPc}$ films with the film structure.

\section{Acknowledgements}

To the Unit of Nanometric Techniques in the Serveis Científico-Tècnics (UB), and to project CTQ2007-68101-C02-02 (Spain) 


\section{References}

[1] S. Palacin, Phthalocyanines in Langmuir and Langmuir-Blodgett films: from molecular design to supramolecular architecture, Adv. Colloids Interf. Sci. 87 (2000) 165.

[2] T-H. Chou, C-H. Chang, Thermodynamic behaviour and relaxation processes of mixed DPPC/cholesterol monolayers at the air/water interface, Colloids Surf. B 17 (2000) 71.

[3] W. Lu, W. Guo, H. Zhou, P. He, Component-controllable mixed monolayer and Langmuir-Blodgett films of $\mathrm{Ru}(\text { dpphen })_{2}{ }^{2+}$ and arachidic acid, Langmuir 16 (2000) 5137.

[4] F. Da Cruz, F. Armand, P-A. Albouy, M. Nierlich, A. Ruaudel-Teixier, Organization of a new tetraalkyl porphyrin by the Langmuir-Blodgett technique, Langmuir 15 (1999) 3653.

[5] J.B. Peng, G.J. Foran, G.T. Barnes, M.J. Crossley, I.R. Gentle, Structures of mixed Langmuir-Blodgett films of tetrakis(3,5-di-tert-butylphenyl)porphinatocopper(II) with cadmium arachidate: a grazing incidence synchrotron x-ray diffraction study, Langmuir $16(2000) 607$.

[6] C-W. Sheu, K-M. Lin, I-H. Ku, C-H. Chang, Y-L. Lee, Y-M. Yang, J-R. Maa, On the Langmuir-Blodgett transfer of copper tetra-tert-butylphthalocyanine monolayers in the presence of arachidic acid, Colloids Surf. A 207 (2002) 81.

[7] T. del Caño, R. Aroca, J.A. de Saja, M.L. Rodríguez-Mendez, Langmuir-Blodgett mixed films of titanyl(IV)phthalocyanine and arachidic acid. Molecular orientation and film structure, Langmuir 19 (2003) 3747.

[8] Y. Tatewaki, T. Akutagawa, T. Nakamura, H. Hasegawa, S. Mashiko, C.A. Christensen, J. Becher, Molecular-assembly nanostructure of 1:1 mixed LangmuirBlodgett films of amphiphilic bis-TTF macrocycle and F-TCNQ, Colloids Surf. A 284285 (2006) 631.

[9] P. Viswanath, K.A. Suresh, Photoinduced phase separation and miscibility in the condensed phase of a mixed Langmuir monolayer, Langmuir 20 (2004) 8149.

[10] S. Martín, P. Cea, G. Pera, M. Haro, M.C. López, Pure and mixed films of a nitrostibene derivative at the air-water interface, Langmuir-Blodgett multilayer fabrication, and optical characterization, J. Colloid Interf. Sci. 308 (2007) 239. 
[11] M. Haro, B. Giner, C. Lafuente, M.C. López, F.M. Royo, P. Cea, Proton sponge and fatty acid interaction at the air-water interface. Thermodynamic, spectroscopic, and microscopic study, Langmuir 21 (2005) 2796.

[12] Y. Cheng, W. Song, J. Cheng, B. Zhao, Studies of the structure and miscibility of mixed Langmuir-Blodgett films of a double-armed dibenzo-18-crown-6 ether with stearic acid, J. Colloid Interf. Sci. 307 (2007) 447.

[13] K. Wojciechowski, D. Grigoriev, R. Ferdani, G.W. Gokel, Mixed monolayers of alkylated azacrown ethers and palmitic acid at the air-water surface, Langmuir 22 (2006) 8409.

[14] M. Pérez-Morales, J.M. Pedrosa, M.T. Martín-Romero, D. Möbius, L. Camacho, Reversible trilayer formation at the air-water interface from a mixed monolayer containing a cationic lipid and an anionic porphyrin, J. Phys. Chem. B 108 (2004) 4457. [15] G. de Miguel, M. Pérez-Morales, M.T. Martín-Romero, E. Muñoz, T.H.

Richardson, L. Camacho, J-aggregation of a water-soluble tetracationic porphyrin in mixed Langmuir-Blodgett films with a calix[8]arene carboxylic acid derivative, Langmuir 23 (2007) 3794.

[16] J. Torrent-Burgués, G. Oncins, F. Sanz, Study of mixed Langmuir and LangmuirBlodgett films of dissimilar components by AFM and force spectroscopy, Colloids Surf. A 321 (2008) 70 .

[17] J. Torrent-Burgués, G. Oncins, F. Sanz, Nanomechanics of Langmuir-Blodgett films, Contributions to Science 4(2) (2008) 177.

[18] B.W. Gregory, D. Vaknin, J.D. Gray, B.M. Ocko, T.M. Cotton, W.S. Struve, Twodimensional crystallization of phthalocyanine pigments at the air/water interface, J. Phys. Chem. B 103 (1999) 502.

[19] K. Labuszewska, R. Cegielski, M. Niedbalska, T. Martynski, Stilbazolium merocyanine systems in Langmuir and Langmuir-Blodgett films molecular layers, Colloids Surf. A 321 (2008) 39.

[20] S.M. O'Flaherty, L. Wiegart, O. Konovalov, B. Struth, Observation of zinc phthalocyanine aggregates on a water surface using grazing incidence x-ray scattering, Langmuir 21 (2005) 11161.

[21] G. de la Torre, C.G. Claessens, T. Torres, Phthalocyanines: old dyes, new materials. Putting color in nanotechnology, Chem. Comm. 20 (2007) 2000.

[22] Q. Wang, W.M. Campbell, E.E. Bonfantani, K.W. Jolley, D.L. Officer, P.J. Walsh, K. Gordon, R. Humphry-Baker, M.K. Nazeeruddin, M. Grätzel, Efficient light 
harvesting by using green $\mathrm{Zn}$-porphyrin-sensitized nanocrystalline $\mathrm{TiO}_{2}$ films, J. Phys. Chem. B 109 (2005) 15397.

[23] L. Valli, Phthalocyanine-based Langmuir-Blodgett films as chemical sensors, Adv. Colloid Interf. Sci. 116 (2005) 13.

[24] V. Gadenne, M. Bayo-Bangoura, L. Porte, L. Patrone, Solvent induced aggregation of protoporphyrin and octacarboxylphthalocyanine of zinc deposited on gold surface, J. Colloid Interf. Sci. in press, DOI 10.1016/j.jcis.2011.03.073

[25] C. Schünemann, C. Elschner, A.A. Levin, M. Levichkova, K. Leo, M. Riede, Zinc phthalocyanine. Influence of substrate temperature, film thickness, and kind of substrate on the morphology, Thin Solid Films 519 (2011) 3939.

[26] B. Schöllhorn, J.P. Germain, A. Pauly, C. Maleysson, J.P. Blanc, Influence of peripheral electron-withdrawing substituents on the conductivity of zinc phthalocyanine in the presence of gases. Part 1: reducing gases, Thin Solid Films 326 (1998) 245.

[27] A. Grofcsik, P. Baranyai, I. Bitter, V. Csokai, M. Kubinyi, K. Szegletes, J. Tatai, T. Vidóczy, Triple state properties of tetrasubstituted zinc phthalocyanine derivatives, J. Mol. Struct. 704 (2004) 11.

[28] C. Hadjur, G. Wagnières, F. Ihringer, Ph. Monnier, H. van der Bergh, Production of the free radicals $\mathrm{O}_{2}{ }^{--}$and $\mathrm{OH}$ by irradiation of the photosensitizer zinc(II) phthalocyanine, J. Photochem. Photobiol. B 38 (1997) 196.

[29] N. Kawashima, N. Nakajima, Effect of photoactive pigment on photodynamic therapy for cancer cells, Progress Org. Coat. 72 (2011) 34.

[30] E.J. Osburn, L-K. Chau, S-Y. Chen, N. Collins, D.F. O’Brien, N.R. Armstrong, Novel amphiphilic phthalocyanines: formation of Langmuir-Blodgett and cast thin films, Langmuir 12 (1996) 4784.

[31] S. Fouriaux, F. Armand, O. Araspin, A. Ruaudel-Teixier, E.M. Maya, P. Vazquez, T. Torres, Effect of the metal on the organization of tetraamidometallophthalocyanines in Langmuir-Blodgett films, J. Phys. Chem. 100 (1996) 16984.

[32] M.I. Gobernado-Mitre, R. Aroca, J.A. DeSaja, Surface pressure-Area isotherms of copper tetra-tert-butylphthalocyanine, Langmuir 11 (1995) 547.

[33] J.P. Bourgoin, F. Doublet, S. Palacin, M. Vandevyver, High In-plane anisotropy in phthalocyanine Langmuir-Blodgett films, Langmuir 12 (1996) 6473.

[34] L. Gaffo, V. Zucolotto, M.R. Cordeiro, W.C. Moreira, O.N. Oliveira Jr., F. Cerdeira, M.J.S.P. Brasil, Structural aspects of Langmuir-Blodgett and cast films of 
zinc phthalocyanine and zinc hexadecafluorophthalocyanine, Thin Solid Films (2007) 7307.

[35] J. Souto, Y. Gorbunova, M.L. Rodríguez-Méndez, S. Kudrevich, J.E. van Lier, J.A. de Saja, Langmuir-Blodgett film formation and spectroscopic characterization of sulphonated derivatives of zinc phthalocyanine, J. Raman Spectroscopy 27 (1996) 649. [36] L-C. Chen, C-C. Wang, C-B. Cheng, Influence of dopant and polymeric matrix on indium tin oxide/p-zinc phthalocyanine/n-Si hybrid solar cells, Thin Solid Films 517 (2009) 1790.

[37] J. Torrent-Burgués, G. Oncins, S. Garcia-Manyes, F. Sanz, Nanotribology on supported lipid bilayers and Langmuir-Blodgett films, Chapter 5 in Biomimetics in Biophysics: Model Systems, Experimental Techniques and Computation, 2010, Ed J.L. Toca-Herrera, Research Signpost, Trivandrum, India.

[38] Veeco Instruments Inc., www.veeco.com.

[39] J.T. Davies, E.K. Rideal, Interfacial phenomena, Academic Press, NY 1993.

[40] G. Oncins, J. Torrent-Burgués, F. Sanz, Mechanical properties of arachidic acid Langmuir-Blodgett films, J. Phys. Chem. C 112 (2008) 1967.

[41] A. Dhanabalan, L. Gaffo, A.M. Barros, W.C. Moreira, O.N. Oliveira Jr., Surface pressure and surface potential isotherms of Yterbium bisphthalocyanine Langmuir monolayers, Langmuir 15 (1999) 3944.

[42] A. Boguta, D. Wróbel, A. Bartczak, R. Swietlik, Z. Stachowiak, R.M. Ion, Characterization of interfacial effects in organic macrocycles Langmuir and LangmuirBlodgett layers studied by surface potential and FT-IR spectroscopy examination, Mat. Sci. Eng. B 113 (2004) 99.

[43] J. Torrent-Burgués, P. Cea, E. Guaus, I. Giner, Characterization of Langmuir and Langmuir-Blodgett films of an octasubstituted zinc phthalocyanine, in preparation. [44] Q. Liu, H. Liu, Y. Bian, X. Wang, Y. Chen, J. Jiang, X. Li, Two-dimensional "nano-ring and nano-crystal" morphologies in Langmuir monolayers of phthalocyanine nickel complexes, J. Colloid Interf. Sci. 300 (2006) 298.

[45] T. Ishikawa, M. Ejaz, Y. Tsujii, H. Shibata, M. Matsumoto, Phase-separated structures of mixed Langmuir-Blodgett films of silano-coupling agents with polymerization initiating groups and amphiphilic carboxylic acids, Colloid Surf. A 321 (2008) 76. 


\section{Captions for figures}

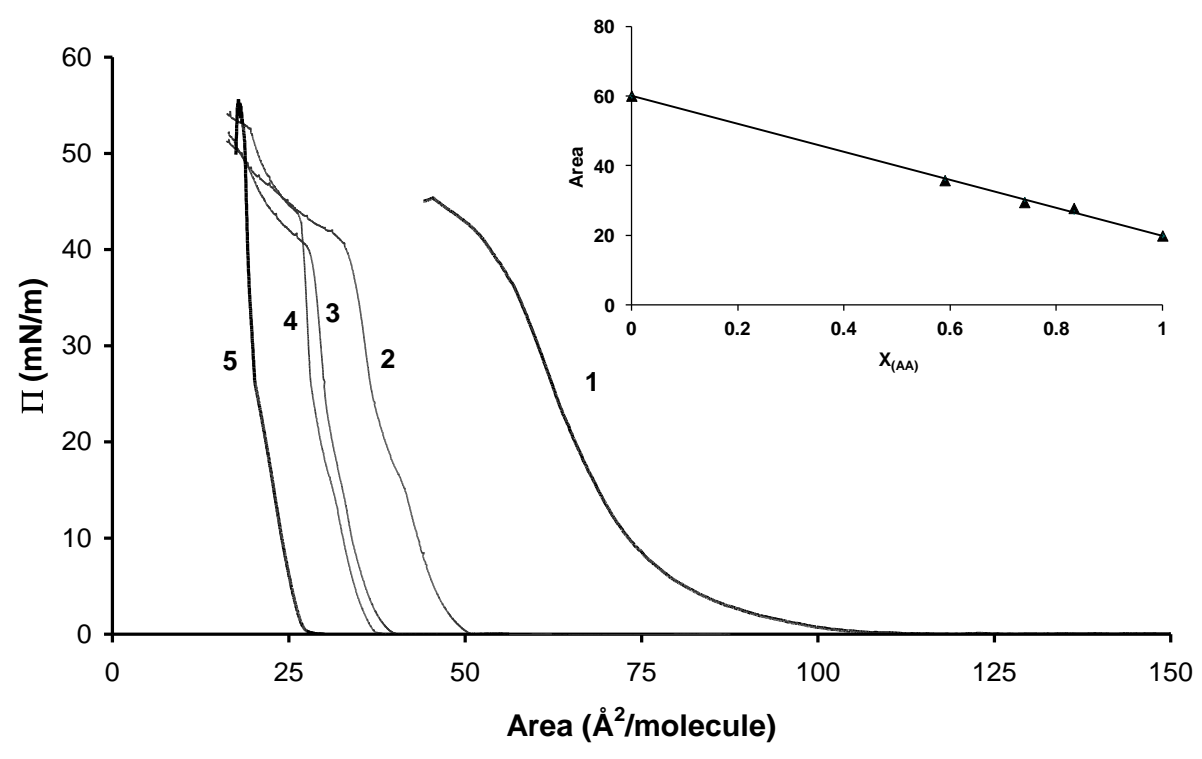

Figure 1. Surface pressure-mean area per molecule isotherms for mixtures of arachidic acid (AA) and tetra-tert-butylphthalocyanine of zinc (tbuPcZn) at $23^{\circ} \mathrm{C}: 1$ ) pure tbuPcZn, 2) $\left.\left.\left.\mathrm{X}_{\mathrm{AA}}=0.59,3\right) \mathrm{X}_{\mathrm{AA}}=0.74,4\right) \mathrm{X}_{\mathrm{AA}}=0.833,5\right)$ pure $\mathrm{AA}$. Inset: Mean area per molecule versus composition for mixtures of AA and tbuPcZn at $\Pi=30 \mathrm{mN} / \mathrm{m}$ (straight line corresponds to the additivity rule). 


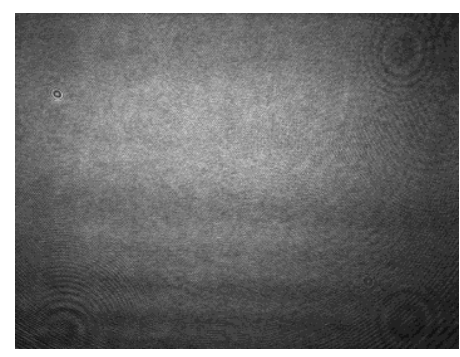

a

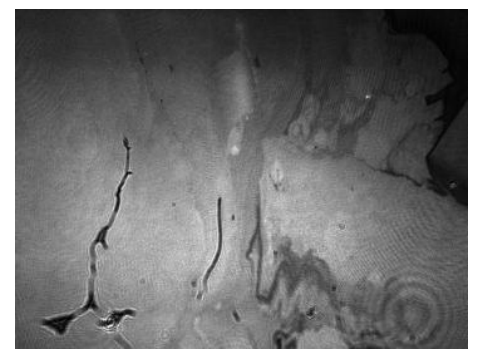

C

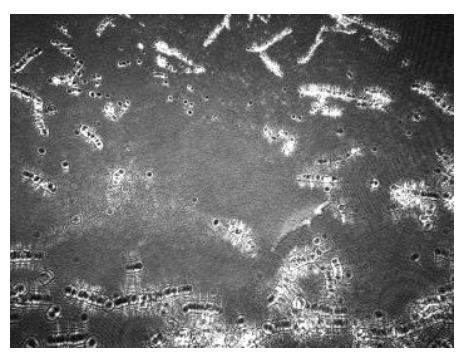

b

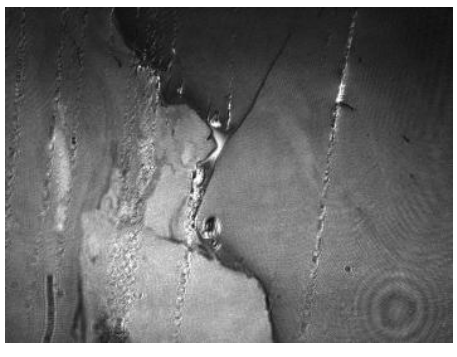

d

Figure 2A. BAM images (3.6 mm x $4.1 \mathrm{~mm}$ ) of an AA film at $\Pi=17$ (a) and $55 \mathrm{mN} / \mathrm{m}$ (collapse) (b), and of a tbuPcZn film at $\Pi=21$ (c) and $43 \mathrm{mN} / \mathrm{m}$ (collapse) (d).

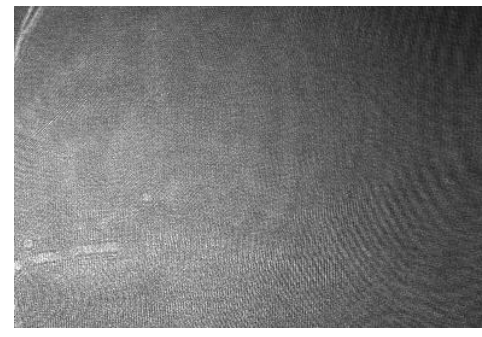

a

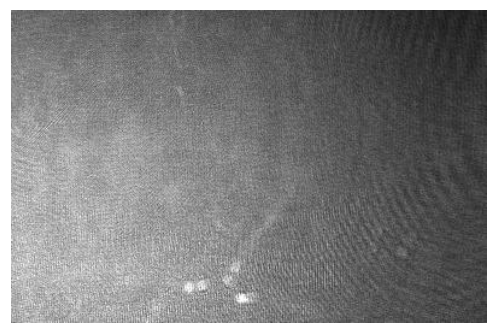

c

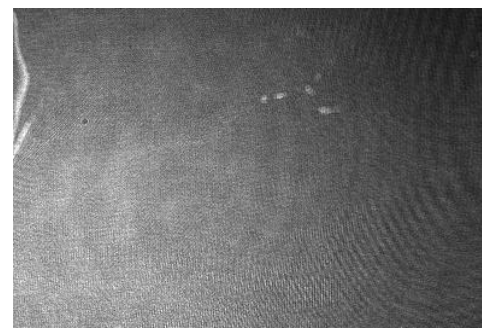

b

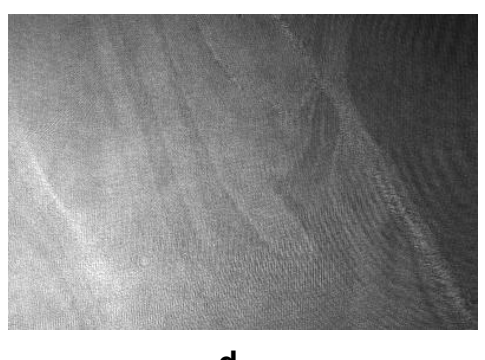

d

Figure 2B. BAM images, size $2.2 \mathrm{~mm} \times 2.2 \mathrm{~mm}$, for the mixed film of AA and tbuPcZn $\left(X_{A A}=0.74\right.$, isotherm $n^{\circ} 3$ in Figure 1), at $\Pi=20.4$ (a), 30 (b), 43.4 (c), and 54.2 mN/m (d). 


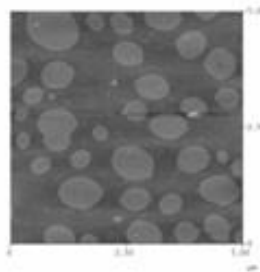

a

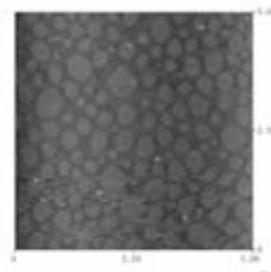

b

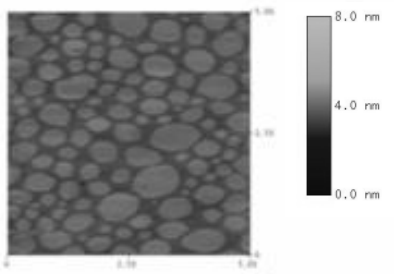

C

Figure 3. AFM images, size $5 \mu \mathrm{m} \times 5 \mu \mathrm{m}$, of LB films transferred onto mica at $\Pi=20 \mathrm{mN} / \mathrm{m}$ of mixed AA and tbuPcZn: $\mathrm{X}_{\mathrm{AA}}=0.59$ (a), 0.74 (b), and 0.833 (c). As is discussed in the text, domains, which are higher, corresponds to AA.

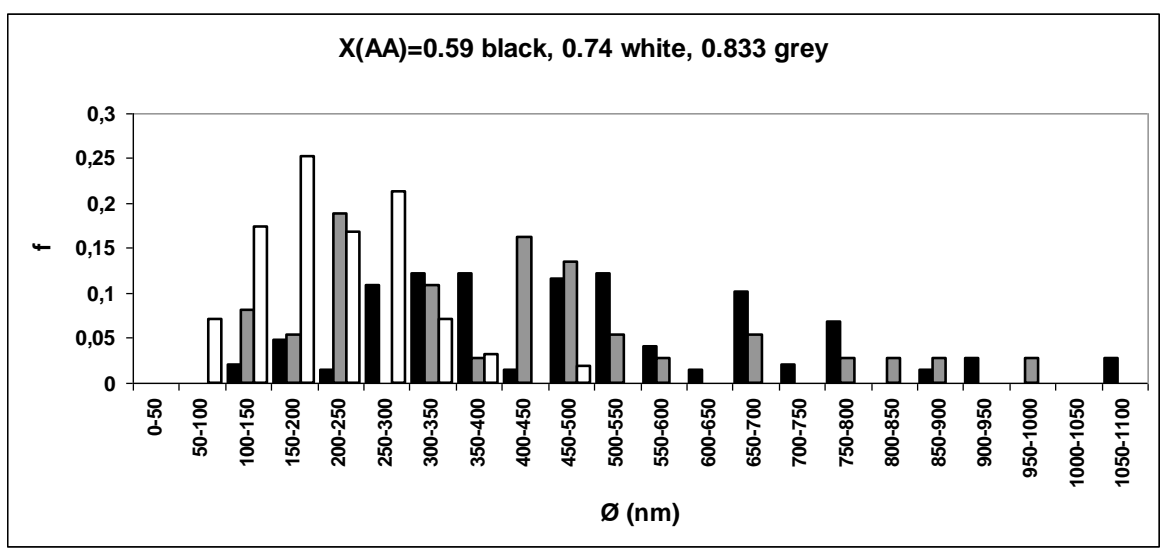

Figure 4. Size distribution of AA domains observed by AFM in the mixed films: $X_{A A}=0.59$ (black), 0.74 (white), and 0.833 (grey). $\mathrm{X}$ axe represents the domain diameter, $\varnothing$, and $\mathrm{Y}$ axe the relative frequency, f. Measurements were made over several AFM images. 


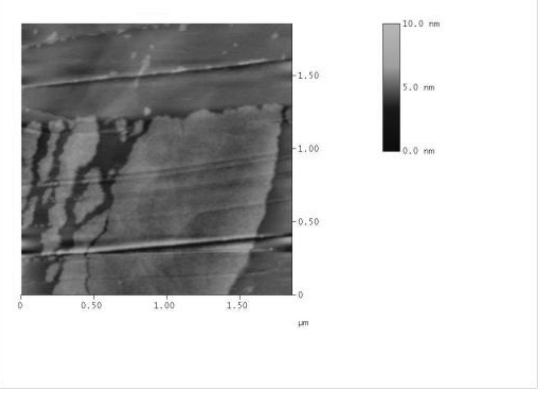

Figure 5. AFM image $\left(2 \times 2 \mu \mathrm{m}^{2}\right)$ of a LB film of tbuPcZn at $\Pi=20 \mathrm{mN} / \mathrm{m}$.

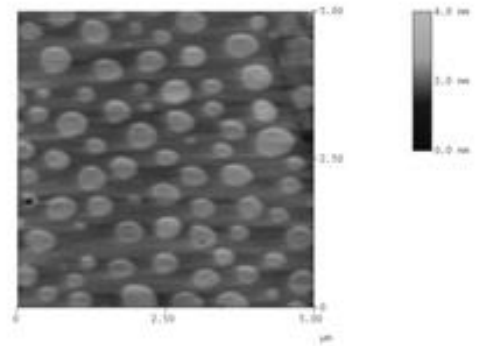

a

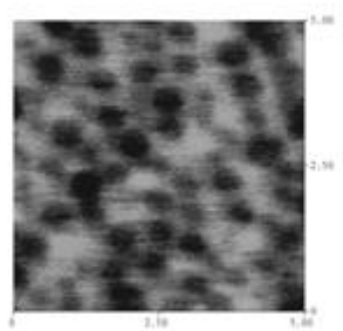

b

Figure 6. Topographic-AFM (a) and surface potential-AFM (b) images $\left(5 \mathrm{x} 5 \mu \mathrm{m}^{2}\right)$ of a LB film, transferred on mica at $\Pi=20 \mathrm{mN} / \mathrm{m}$, of mixed AA and tbuPcZn $\left(X_{\mathrm{AA}}=0.833\right)$. Lower surface potential is observed in the AA domains. 


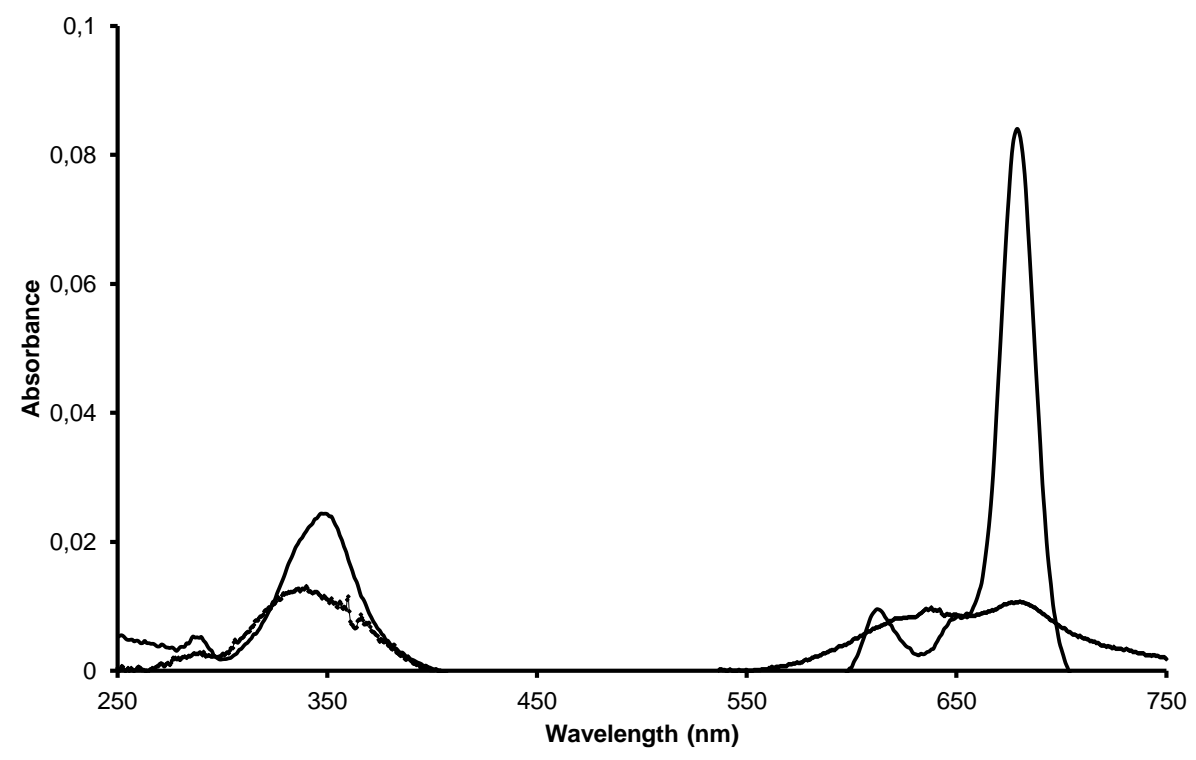

Figure 7. UV-Vis spectra for tbuPcZn in a $0.610^{-5} \mathrm{M}$ solution (thin line) and in a one-layer LB film (thick line).

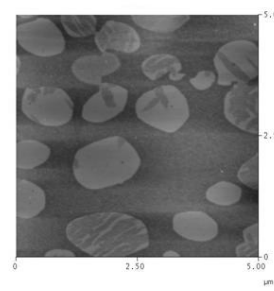

a

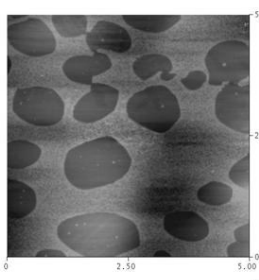

b

Figure 8. Topographic-AFM (a) and friction (b) images $\left(5 \times 5 \mu \mathrm{m}^{2}\right)$ of an aged sample, two months, of mixed AA and tbuPcZn $\left(\mathrm{X}_{\mathrm{AA}}=0.74\right)$. Lower friction is observed in the AA domains. 